\title{
SUCOS DE LARANJA INDUSTRIALIZADOS E PREPARADOS SÓLIDOS PARA REFRESCOS: ESTABILIDADE QUÍMICA E FÍSICO-QUIMMICA
}

\author{
Patricia T. SILVA, Eliane FIALHO², Maria Lúcia M. LOPES', Vera Lúcia VALENTE-MESQUITA
}

\section{RESUMO}

O suco de laranja in natura é considerado uma das melhores fontes de vitamina $\mathrm{C}$ da dieta. No entanto, o ritmo de vida acelerado da sociedade atual associado à praticidade de preparo e armazenamento tem levado ao aumento do consumo de sucos e refrescos industrializados, porém pouco se conhece sobre a estabilidade destes produtos. Com o objetivo de avaliar a estabilidade de sucos de laranja prontos para o consumo (SPC) e de refrescos elaborados a partir de preparados sólidos (PSR), foram determinados os teores de ácido ascórbico (AA) e de sólidos solúveis totais (SST), a acidez total titulável (ATT) e o pH. O teor de AA dos SPC variou de $17,25 \mathrm{mg} \%$ a $62,40 \mathrm{mg} \%(\mathrm{p}=0,05)$. Duas amostras apresentaram teor de AA inferior ao mínimo estabelecido pela legislação. Para os refrescos elaborados a partir dos PSR, o teor de AA variou entre $0,67 \mathrm{mg} \%$ e $32,00 \mathrm{mg} \%(\mathrm{p}=0,05)$. O pH e o teor de SST mantiveram-se constantes, enquanto que a ATT apresentou variações durante o armazenamento. Os SPC podem ser considerados como fonte de vitamina C, ao contrário da maioria dos refrescos elaborados a partir dos PSR que não podem ser considerados fontes importantes desta vitamina.

Palavras-chave: laranja; sucos industrializados; refrescos; ácido ascórbico; estabilidade.

\section{SUMMARY}

INDUSTRIALIZED ORANGE JUICES AND REFRESHMENT PREPARED FROM ORANGE JUICE POWDER: CHEMICAL AND PHYSICOCHEMICAL STABILITY. Fresh orange juice is considered to be one of the best sources of vitamin C. Nevertheless, hand squeezed juice is often inconvenient for consumers who seek practical and fast ways to prepare their meals. The objective of this study was to analyze the chemical and physicochemical stability of ready to drink and refreshments prepared from orange juice powder commercially available in the city of Rio de Janeiro. The ascorbic acid (AA) content, total soluble solids (TSS), total tritatable acidity (TAA) and $\mathrm{pH}$ were determined. The AA content of ready to drink orange juice ranged from $17.25 \mathrm{mg} \%$ to $62.40 \mathrm{mg}$ $(p=0.05)$. In two batches the AA content was lower than that established by the Brazilian legislation. The AA content of refreshments prepared from orange juice powder ranged from $0.67 \mathrm{mg} \%$ to $32.00 \mathrm{mg} \%$ among samples $(\mathrm{p}=0.05)$. TSS and $\mathrm{pH}$ values were stable, while TTA changed during the storage time. Industrialized ready to drink orange juices may be considered a source of vitamin C, whereas most of the cheaper refreshments prepared from powder orange juice are not.

Keywords: orange; industrialized juices; refreshments; ascorbic acid; stability.

\section{1 - INTRODUÇÃO}

O Brasil ocupa, atualmente, o primeiro lugar na produção mundial de laranja [9]. O suco desta fruta é considerado uma das melhores fontes de vitamina $\mathrm{C}$ (ou ácido ascórbico - AA) da dieta [22], aumentando sua demanda por consumidores que procuram produtos frescos e funcionais para compor uma alimentação saudável [15].

A elaboração manual de sucos de frutas tornou-se um inconveniente ao ritmo de vida acelerado da sociedade [15]. Por isso, o consumidor brasileiro tem demonstrado interesse crescente em consumir produtos "prontos para o consumo", o que impulsionou, a partir da década de 90, o surgimento de diversas marcas comerciais de sucos de frutas industrializados no mercado nacional [17].

Recebido para publicação em 02/05/2005. Aceito para publicação em 31/08/2005 (001519).

Departamento de Nutrição Básica e Experimental, Instituto de Nutrição Josué de Castro, Universidade Federal do Rio de Janeiro. Endereço: Av. Bauhinia, 400, Centro de Ciências da Saúde, Bloco J, Ilha da Cidade Universitária, CEP: 21941-590, Rio de Janeiro-RJ, Brasil.E-mail:vvalente@nbe.ufri.br

A quem a correspondência deve ser enviada.
Como conseqüência, tais sucos ganham espaço cada vez maior nas gôndolas de supermercados e nos lares dos brasileiros. Cada brasileiro consome, em média, 2 litros de SPC por ano, volume inferior à média de países desenvolvidos, como Portugal e Espanha, em que chega a 24 litros/ano/pessoa [24].

Os preparados sólidos para refresco (PSR) são utilizados no preparo de bebidas, devendo ser dissolvidos em água fria, simulando o sabor do suco de fruta natural. Entre as vantagens do consumo destes produtos estão as facilidades de estocagem e de preparo, além da grande aceitação por adultos e crianças $[8,18]$. Os PSR são utilizados em mais de $54 \%$ dos lares brasileiros, com um consumo anual per capita de 16L. De acordo com uma pesquisa de hábitos alimentares realizada no Brasil, os PSR são considerados itens da cesta básica e constitui alternativa econômica em relação a sucos prontos e refrigerantes [1].

Devido ao avanço tecnológico, muitos alimentos vêm sendo conservados com o objetivo de evitar alterações que possam comprometer as características nutricionais, microbiológicos e sensoriais. Os sucos industrializados, para serem considerados de boa qualidade, devem apresentar atributos semelhantes ao do produto in natura [17]. No entanto, pode ocorrer degradação, especialmente do AA, em conseqüência do tratamento térmico e da temperatura de estocagem [13]. GRAUMLICH, MARCY \& ADAMS [10] observaram que a temperatura de 
estocagem foi o fator mais importante para a determinação da vida-de-prateleira do suco de laranja, independente do tipo de processamento a que foram submetidos.

O AA é usado como índice de qualidade nutricional dos produtos derivados de frutas e vegetais porque, comparado a outros nutrientes, esta vitamina é mais sensivel à degradação durante o processamento e subseqüente estocagem [19]. Tratamentos como pasteurização, esterilização e alta pressão hidrostática, podem ser aplicados na conservação de sucos de frutas [20]. O processo de desidratação é ainda aplicado na elaboração dos PSR [18]. No entanto, este processo, se realizado de maneira inadequada, pode causar sérios danos às características sensoriais e nutricionais do produto desidratado [8].

O suco de laranja é definido como a bebida não fermentada e não diluída, obtida da parte comestivel da laranja (Citrus sinensis) através de processo tecnológico adequado. Dentre outras características, este suco deve apresentar teores mínimos de AA e de sólidos solúveis totais (SST), de $25,00 \mathrm{mg} \%$ e de $10,5^{\circ} \mathrm{Brix}$, respectivamente, além de uma relação SST/acidez total titulável (ATT), em g/ $100 \mathrm{~g}$ de ácido cítrico anidro, minima de 7,0 [4]. Já os PSR, são definidos como produtos à base de suco ou extrato vegetal de sua origem e açúcares, podendo ser adicionado de edulcorantes hipocalóricos e não-calóricos, destinado à elaboração de bebida para consumo imediato, pela adição de água potável. Pode conter em sua composição suco ou polpa de fruta desidratada, açúcares e edulcorantes artificiais, aromatizantes aprovados pela legislação e devem apresentar características sensoriais e físico-químicas compativeis com a composição do produto. Os PSR devem conter uma quantidade minima de suco desidratado da fruta de $5 \%$ em peso [5].

Embora alguns autores tenham avaliado o teor de AA em sucos prontos para o consumo, poucos são os estudos que acompanharam a estabilidade desta vitamina durante o armazenamento, após a abertura da embalagem $[12,13,15]$. Além disso, é importante destacar a escassez de trabalhos publicados referentes ao teor de AA e à estabilidade química dos refrescos elaborados a partir de preparados sólidos.

Este trabalho teve por objetivo avaliar a estabilidade química e físico-química de diferentes marcas de sucos industrializados prontos para o consumo, bem como de refrescos elaborados a partir de preparados sólidos, durante armazenamento sob refrigeração.

\section{2 - MATERIAL E MÉTODOS}

\section{1 - Amostras}

Dez amostras de SPC e onze amostras de PSR, sabor laranja foram adquiridas em mercado varejista da cidade do Rio de Janeiro, Brasil, e transportadas para o Laboratório de Análise e Processamento de Alimentos (LAPAL), do Instituto de Nutrição Josué de Castro/UFRJ.

Os SPC foram armazenados nas próprias embala- gens, sob refrigeração $\left(4^{\circ} \mathrm{C}\right)$ e submetidos às análises quîmicas e físico-químicas durante 72 horas.

Os PSR foram diluídos em água filtrada, de acordo com as recomendações do fabricante especificadas na embalagem do produto. Os refrescos foram acondicionados em garrafas de vidro transparente, previamente higienizadas, fechadas, armazenadas em refrigerador doméstico $\left(4^{\circ} \mathrm{C}\right)$, para serem analisados durante 48 horas.

\section{2 - Métodos}

\subsection{1 -Análises químicas}

O teor de ácido ascórbico (AA), expresso em mg de AA/ $100 \mathrm{~mL}$ de suco, foi determinado, em triplicata, pelo método de Tillmans [2] modificado por BENASSI \& ANTUNES [3], que utilizaram solução de ácido oxálico como solvente, em substituição ao ácido metafosfórico. A acidez total titulável (ATT), expressa em gramas de ácido cítrico anidro/100g de suco, foi determinada, em triplicata, por titulação com $\mathrm{NaOH} 0,1 \mathrm{~N}$ [11].

\subsection{2 - Análises físico-químicas}

$\mathrm{O} \mathrm{pH}$ foi determinado em pHmetro digital Incibrás, com compensação automática de temperatura. A quantificação dos sólidos solúveis totais (SST), expressa em ${ }^{\circ} \mathrm{Brix}$, foi realizada por meio de leitura em refratômetro Eppendorf 2763 [11].

\subsection{3 - Análises estatísticas}

Os resultados obtidos foram submetidos à análise de regressão e à análise de variância ANOVA, sendo as médias comparadas pelo teste de Tukey $(p=0,05)$. O software estatístico utilizado foi Excel 2000 (Microsoft).

\section{3 - RESULTADOS E DISCUSSÃO}

\section{1 - Suco de laranja industrializado}

A Tabela 1 mostra o teor médio de AA nas dez marcas de suco de laranja industrializado, logo após a abertura das embalagens, bem como o volume de suco necessário para atingir a ingestão dietética de referência (IDR = 90mg) para homens adultos, a partir de 19 anos [7]. Foi observada variabilidade entre os teores de AA das amostras, que se apresentaram entre $17,25 \mathrm{mg} \%$ e 62,40 $\mathrm{mg} \%$. O teor médio de AA foi estatisticamente diferente entre as amostras $(p=0,05)$, exceto para três delas $(2,6 \mathrm{e}$ 7). LIMA, MÉLO \& LIMA [17], estudando a qualidade de três marcas de suco de laranja industrializado, encontraram teores médios de AA entre $45,68 \mathrm{mg} \%$ e $54,34 \mathrm{mg} \%$. Os resultados do presente estudo revelam que para atingir o valor da IDR para homens adultos, seria necessária a ingestão de um volume de suco variável entre $144 \mathrm{~mL}$ e $522 \mathrm{~mL}$. Desta forma, mesmo para a amostra que apresentou o menor teor de AA, a ingestão diária de três copos de suco $(200 \mathrm{~mL})$ seria suficiente para suprir a IDR [7].

De acordo com VALENTE-MESQUITA et al. [25], os 
TABELA 1 - Teor médio inicial de ácido ascórbico (AA) em diferentes marcas de suco de laranja industrializado e volume de suco necessário para atingir a IDR*

\begin{tabular}{|c|c|c|}
\hline $\begin{array}{c}\text { Sucos } \\
\text { Industrializados }\end{array}$ & Teor de AA (mg\%) & $\begin{array}{c}\text { Volume de suco }(\mathrm{mL}) \\
\text { necessário para atingir a IDR* }\end{array}$ \\
\hline 9 & $62,40^{a} \pm 0,33$ & 144 \\
\hline 5 & 47,28 b $\pm 0,33$ & 190 \\
\hline 4 & $38,12^{\circ} \pm 0,57$ & 236 \\
\hline 3 & $34,88 \mathrm{~d} \pm 0$ & 258 \\
\hline 10 & $29,46^{\circ} \pm 0,33$ & 306 \\
\hline 6 & $27,52+ \pm 0,33$ & 327 \\
\hline 7 & $26,94 f \pm 0,34$ & 334 \\
\hline 2 & $26,94^{\prime} \pm 0,34$ & 334 \\
\hline 8 & $24,428 \pm 0$ & 369 \\
\hline 1 & $17,25^{\mathrm{h}} \pm 0,33$ & 522 \\
\hline
\end{tabular}

teores de AA encontrados em sucos de laranja industrializados demonstram a importância de seu valor nutritivo, principalmente no que diz respeito ao atendimento às recomendações nutricionais, uma vez que apresentam crescente aceitação pela população brasileira. Dados de recente pesquisa revelam que o suco pronto para o consumo está presente em 30\% dos lares brasileiros [24].

Avaliando comparativamente o teor de AA das amostras de suco industrializado e o teor de AA descrito nos rótulos das embalagens, verifica-se que nas amostras 1,3 , 6, 7 e 8, os teores médios de AA analisados foram, respectivamente, $47,7 \%, 8,2 \%, 21,4 \%, 10,2 \%$ e $45,7 \%$ inferiores ao descrito na embalagem, enquanto que a amostra 4 apresentou teor de AA 19,1\% superior ao indicado no rótulo (Figura 1). Nas embalagens das amostras 2, 5, 9 e 10 não havia indicação do teor de vitamina $\mathrm{C}$ no produto. $\hat{\mathrm{E}}$ importante ressaltar que o teor médio de AA das amostras 1 e $8,17,25 \mathrm{mg} \%$ e $24,42 \mathrm{mg} \%$, respectivamente, não estão em conformidade com a legislação brasileira [4], que estabelece um teor mínimo de 25,00mg\%. Em estudo anterior, VALENTE-MESQUITA et al. [25] observaram que de sete marcas de sucos industrializados, duas não apresentavam o teor de AA nas embalagens, três mencionaram teores superiores àqueles obtidos nas análises e, em uma, o teor de AA mencionado na embalagem foi inferior ao analisado.

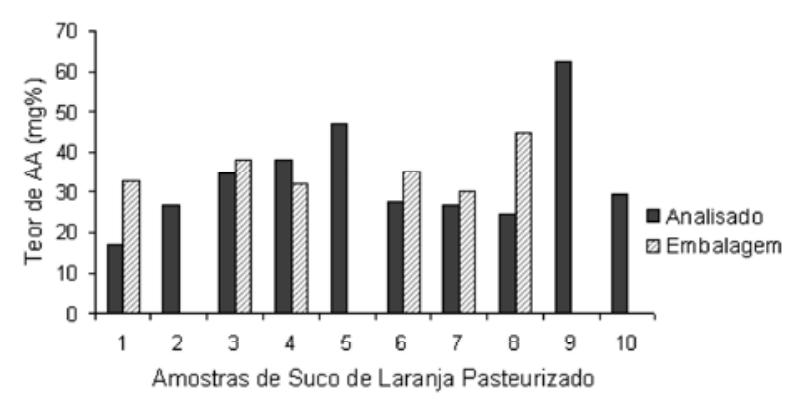

FIGURA 1 - Comparação entre o teor médio de ácido ascórbico (AA) analisado e os indicados no rótulo de sucos de laranja industrializados prontos para o consumo
A Figura 2 mostra a variação no teor de AA das diferentes marcas de SPC durante 72 horas de armazenamento a $4^{\circ} \mathrm{C}$. Embora o teor médio inicial de AA tenha variado entre as amostras, este permaneceu estável ao longo do período das análises. A taxa de redução de AA variou de 0,008 a $0,01 \mathrm{mg} /$ hora, exceto para as amostras 5 , 8 e 9, em que não foi verificada redução no teor deste nutriente durante o período de armazenamento. O percentual de perda desta vitamina variou de zero a 9,5 entre as amostras. KABASAKALIS, SIOPIDOU \& MOSHATOU [13] observaram perda de $9 \%$ de AA em sucos de laranja industrializados, armazenados nas próprias embalagens por 10 dias sob refrigeração, e não verificaram perda desta vitamina em suco de laranja fresco, armazenado sob refrigeração por 2 dias. LAVINAS et al. [14] encontraram percentual médio de perda de AA de $26 \%$ em diferentes sucos de limão industrializados, armazenados sob refrigeração por 2 dias. JOHNSTON \& BOWLING [12], estudando a estabilidade do AA em sucos de laranja disponíveis comercialmente no Arizona, observaram que o SPC permaneceu sem alteração de valor nutricional por uma semana depois de aberto.

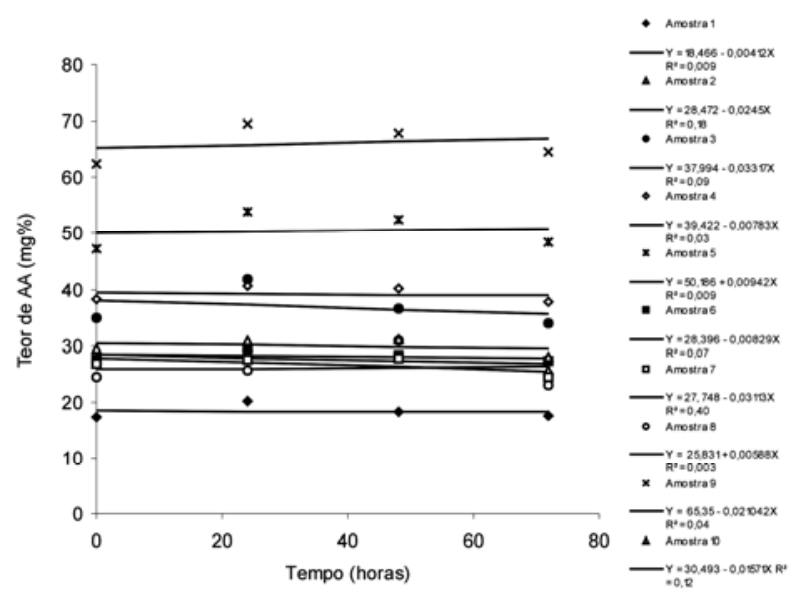

FIGURA 2 - Teor médio de ácido ascórbico (AA) em diferentes marcas de suco de laranja industrializado pronto para o consumo, armazenados sob refrigeração $\left(4^{\circ} \mathrm{C}\right)$ durante 72 horas

A Tabela 2 mostra os valores de $\mathrm{pH}$ das amostras de sucos industrializados durante as 72 horas de armazenamento sob refrigeração. Os resultados das análises do $\mathrm{pH}$, obtidos logo após a abertura das embalagens (tempo zero), variaram entre 3,51 e 4,02. Estes valores encontram-se dentro da faixa de $\mathrm{pH}$ característica de frutas cítricas, que varia de 3,40 a 4,00 [6]. SADLER, PARISH \& WICKER [21] encontraram valores de $\mathrm{pH}$ de 3,52 e 3,78 em duas amostras de suco de laranja industrializado. Segundo LEITÃO [16], o pH é o fator que exerce maior efeito seletivo sobre os microrganismos presentes no suco de laranja, o que possibilita a aplicação de um processo de pasteurização mais brando. A legislação brasileira [4] não estabelece um valor mínimo de $\mathrm{pH}$ como padrão de identidade e qualidade para o suco de laranja. 
TABELA 2 - Determinação de pH em sucos de laranja prontos para o consumo (SPC) durante armazenamento sob refrigeração $\left(4^{\circ} \mathrm{C}\right)$

\begin{tabular}{ccccc}
\hline Refrescos & Tempo zero & 24 horas & 48 horas & 72 horas \\
\hline 1 & 3,55 & 4,00 & 3,95 & 3,59 \\
2 & 3,93 & 4,01 & 3,98 & 3,89 \\
3 & 4,02 & 4,00 & 3,99 & 4,00 \\
4 & 3,89 & 3,97 & 4,01 & 3,85 \\
5 & 3,85 & 3,99 & 4,01 & 3,82 \\
6 & 3,91 & 3,99 & 4,02 & 3,90 \\
7 & 3,79 & 4,01 & 4,03 & 3,73 \\
8 & 3,87 & 3,99 & 3,98 & 3,88 \\
9 & 3,55 & 4,00 & 4,00 & 3,50 \\
10 & 3,51 & 4,01 & 4,01 & 3,49 \\
\hline
\end{tabular}

Quando analisadas logo após a abertura das embalagens, as amostras apresentaram teores de SST que variaram de 10,5 a $13,0^{\circ}$ Brix e mantiveram-se constantes durante o período de armazenamento. A ATT variou de 0,67 a 0,96 g\% de ácido cítrico anidro entre as amostras, enquanto a relação SST/ATT variou de 13,07 a 18,84 (Tabela 3). Os valores de SST e a relação SST/ATT estão de acordo com o que é estabelecido pela legislação brasileira vigente para suco de laranja industrializado [4], que preconiza um teor minimo de $10,5^{\circ}$ Brix e 7,0 , respectivamente. LIMA, MÉLO \& LIMA [17] encontraram valores médios de SST de $10,8,10,9$ e $10,2^{\circ}$ Brix e relação SST/ATT de 13,06, 12,96 e 12,79, para três marcas de suco de laranja industrializado. Os resultados de SST e de ATT obtidos no presente estudo foram inferiores aos encontrados por SADLER, PARISH \& WICKER [21], que obtiveram valores de 13,4 e $14,42^{\circ}$ Brix para SST e de 1,26 e $1,09 \mathrm{~g} \%$ de ácido cítrico para ATT, em duas marcas de sucos industrializados. No entanto, os valores obtidos para a relação SST/ATT do presente trabalho, com exceção da amostra 10, foram superiores aos encontrados por SADLER, PARISH \& WICKER [21]. A ATT é um importante parâmetro para indicar a adequação dos processos de conservação de frutas. A decomposição por hidrólise, a oxidação ou a fermentação podem modificar a concentração de íons hidrogênio e, conseqüentemente, a acidez dos produtos elaborados a base de frutas [11]. Contudo, a legislação brasileira vigente [4] não estabelece um valor minimo para este parâmetro.

TABELA 3 - Teor de sólidos solúveis totais (SST), acidez total titulável (ATT) e relação SST / ATT em diferentes marcas de suco de laranja industrializado, analisados logo após a abertura da embalagem

\begin{tabular}{cccc}
\hline Amostras & SST $\left({ }^{\circ}\right.$ Brix) & ATT $(\mathrm{g} \%$ ác. cítrico) & SST $/$ ATT \\
\hline 1 & 12,5 & 0,67 & 18,66 \\
2 & 12,0 & 0,78 & 15,39 \\
3 & 11,5 & 0,82 & 14,02 \\
4 & 11,5 & 0,85 & 13,53 \\
5 & 11,5 & 0,86 & 13,37 \\
6 & 11,5 & 0,78 & 14,74 \\
7 & 13,5 & 0,96 & 14,06 \\
8 & 10,5 & 0,70 & 15,00 \\
9 & 13,0 & 0,69 & 18,84 \\
10 & 11,5 & 0,88 & 13,07 \\
\hline
\end{tabular}

\section{2 - Preparados sólidos para refresco}

A Tabela 4 apresenta o teor médio de AA nas amostras de refresco de laranja, analisadas logo após a dilui- ção dos respectivos preparados sólidos, bem como o volume necessário para atingir a IDR $(90 \mathrm{mg})$ para homens adultos, a partir de 19 anos [7]. O teor de AA entre as amostras variou de 0,67 a $32,00 \mathrm{mg} \%$, tendo sido observada diferença significativa entre algumas delas. Desta forma, o volume de refresco necessário para suprir a IDR desta vitamina para homens adultos variou de 281 a 13.433mL. Embora oito, das onze amostras estudadas mencionem na embalagem que o produto recebeu adição de AA, com exceção da amostra 7, seria necessária a ingestão de 4 a 67 copos (200mL) de refresco para suprir este valor de referência [7]. Os resultados do presente estudo revelam que estes produtos, em geral, não podem ser considerados fontes de vitamina C. VALENTEMESQUITA et al. [25] avaliaram o volume de suco in natura de diferentes cultivares de laranja, como única fonte alimentar de vitamina $\mathrm{C}$, necessário para atingir a IDR e observaram que este volume varia de acordo com a cultivar sem, no entanto, ultrapassar a ingestão de um copo e meio diário.

TABELA 4 - Teor médio de ácido ascórbico (AA) em refrescos de laranja analisados logo após a diluição dos preparados em pó e volume de refresco, necessário para atingir a IDR*

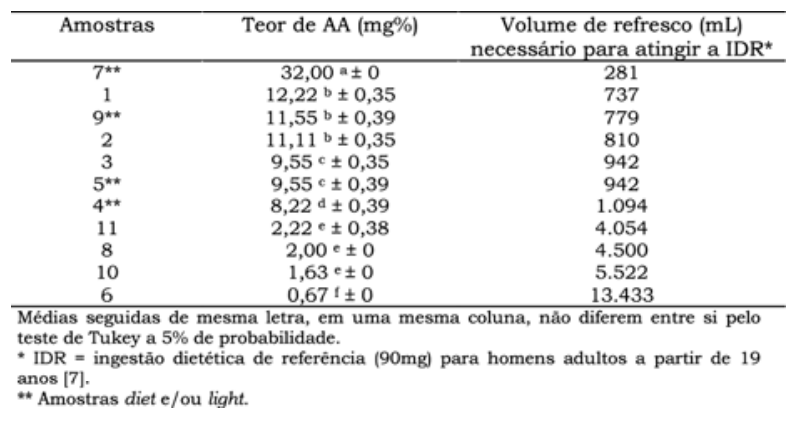

Com relação à estabilidade do AA dos refrescos, foi observado que as amostras 1, 4 e 5 apresentaram as maiores taxas de redução desta vitamina, que foram, respectivamente, $0,10 \mathrm{mg} /$ hora, $0,08 \mathrm{mg} /$ hora e $0,06 \mathrm{mg} /$ hora. Nas demais amostras, o teor de AA permaneceu constante durante as 48 horas de armazenamento, apresentando taxa de redução de AA que variou de 0,003 a $0,03 \mathrm{mg} /$ hora (Figura 3). Duas das quatro amostras diet e/ou light estão entre as que apresentaram maiores taxas de redução de AA. São escassos os trabalhos publicados que avaliem a estabilidade química e físico-química de refrescos, após elaboração dos mesmos a partir dos preparados sólidos. Com a crescente popularização do consumo destes produtos, torna-se importante conhecer o teor de vitamina $\mathrm{C}$, bem como a estabilidade desta, uma vez que os PSR geralmente são utilizados em substituição aos sucos de frutas in natura.

Os valores de $\mathrm{pH}$, assim como o teor de SST e a ATT em refrescos de laranja armazenados sob refrigeração $\left(4^{\circ} \mathrm{C}\right)$ por 48 horas são apresentados na Tabela 5 . O pH das amostras variou de 2,42 a 3,11 no tempo inicial. O teor de SST variou de 0,5 a 5,0 ${ }^{\circ}$ Brix entre as onze amos- 


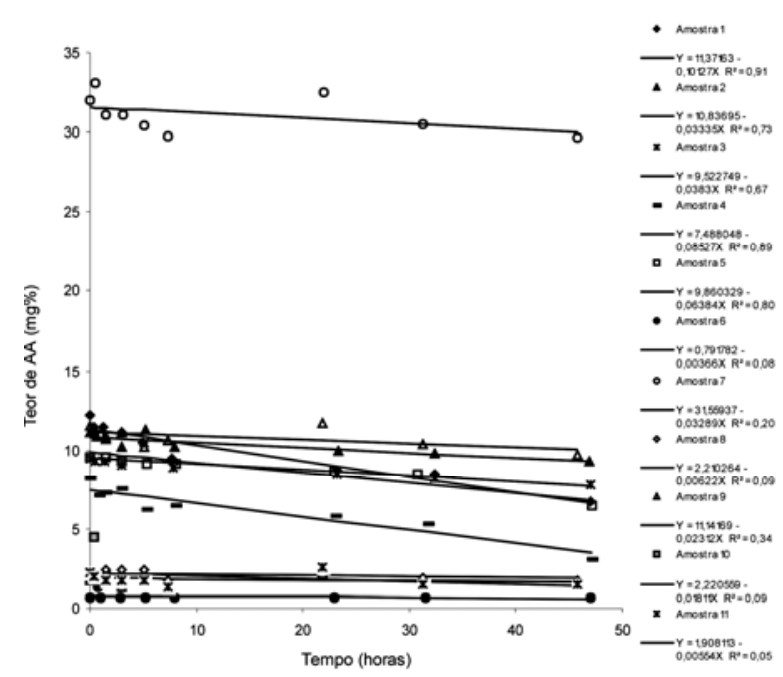

FIGURA 3 - Estabilidade do ácido ascórbico (AA) em refrescos de laranja armazenados sob refrigeração $\left(4^{\circ} \mathrm{C}\right)$ durante 48 horas

tras e, em oito delas, permaneceu constante durante o período sob refrigeração. A ATT das amostras variou de 0,10 a 0,82g\% de ácido cítrico e não apresentou a mesma estabilidade verificada para $\mathrm{pH}$ e SST. Entre as amostras diet e/ou light, a de número 7 foi a que apresentou a ATT menos estável, enquanto o $\mathrm{pH}$ e o teor de SST mantiveram-se estáveis. O pH, o teor de SST e a ATT dos refrescos elaborados a partir dos PSR foram inferiores aos obtidos para os SPC. Estes mesmos parâmetros foram também inferiores àqueles obtidos por SILVA et al. [23] para suco in natura de laranja Pêra. O Regulamento Técnico para Fixação dos Padrões de Identidade e Qualidade para Preparado Sólido para Refresco [5], não estabelece valores mínimos para os parâmetros químicos e físicoquímicos avaliados neste estudo, no produto pronto para o consumo.

TABELA 5 - Determinação do pH, sólidos solúveis totais (SST) e acidez total titulável (ATT) em refrescos de laranja armazenados sob refrigeração $\left(4^{\circ} \mathrm{C}\right)$

\begin{tabular}{ccccccc}
\hline \multirow{2}{*}{ Amostras } & \multicolumn{2}{c}{$\mathrm{pH}$} & \multicolumn{2}{c}{ SST ( ${ }^{\circ}$ Brix) } & \multicolumn{2}{c}{$\begin{array}{c}\text { ATT }(\mathrm{g} \% \\
\text { ac.citrico) }\end{array}$} \\
\cline { 2 - 7 } & To & T48h & To & T48h & To & T48h \\
\hline 1 & 2,62 & 2,62 & 4,5 & 4,5 & 0,45 & 0,58 \\
2 & 2,90 & 2,98 & 4,5 & 4,5 & 0,54 & 0,53 \\
3 & 3,11 & 3,28 & 4,5 & 4,5 & 0,39 & 0,38 \\
$4^{*}$ & 2,78 & 3,00 & 5,0 & 4,5 & 0,58 & 0,58 \\
$5^{*}$ & 2,42 & 2,63 & 1,0 & 1,0 & 0,59 & 0,66 \\
6 & 2,51 & 2,70 & 0,5 & 0,5 & 0,10 & 0,10 \\
$7^{*}$ & 2,76 & 2,79 & 1,0 & 1,0 & 0,58 & 0,25 \\
8 & 2,46 & 2,46 & 2,0 & 2,0 & 0,22 & 0,48 \\
$9^{*}$ & 3,00 & 3,00 & 1,0 & 1,0 & 0,82 & 0,79 \\
10 & 2,91 & 2,90 & 4,5 & 4,75 & 0,49 & 0,21 \\
11 & 2,59 & 2,57 & 1,0 & 2,0 & 0,24 & 0,57 \\
\hline${ }^{*}$ Amostras diet e/ou light & & & & &
\end{tabular}

\section{4 - CONCLUSÕES}

Houve variabilidade entre os teores de AA das amostras de SPC. Das dez amostras analisadas, duas apre- sentaram o teor médio de AA analisado inferior ao minimo estabelecido pelo Ministério da Agricultura. Contudo, a ingestão de até três copos de suco $(200 \mathrm{~mL} / \mathrm{copo})$ seria suficiente para suprir a IDR de vitamina $\mathrm{C}$ para homens adultos a partir dos 19 anos. Em todas as amostras, os demais parâmetros químicos e físico-químicos analisados estavam de acordo com a legislação. O teor de AA dos SPC permaneceu estável ao longo do período de armazenamento.

Tanto o teor quanto a estabilidade do AA entre as amostras de refrescos elaborados a partir dos PSR apresentaram variabilidade significativa. Para suprir a IDR seria necessária a ingestão de, aproximadamente, 1,4 a 68 copos de refresco. A ausência, na legislação brasileira, de parâmetros que regulamentem normas para fixação de padrões de identidade e qualidade para preparados sólidos para refresco impede verificar a adequação dos resultados obtidos.

Os sucos de laranja industrializados prontos para o consumo podem ser considerados como importante fonte de vitamina $\mathrm{C}$, ao contrário da maioria dos refrescos elaborados a partir dos preparados sólidos.

\section{5 - REFERÊNCIAS BIBLIOGRÁFICAS}

[1] AMCHAM. Prático e barato. Revista Update, abr., 2002. Disponivel em:

<http://www.amcham.com.br/revista/revista2002-0320a/materia2003-03-21f/pagina2002-03-21g> Acesso em: 05 mar. 2004.

[2] ASSSOCIATION OF OFFICIAL ANALYTICAL CHEMISTRY. Official methods of analysis. 14. ed. Washington, DC, 1984, cap. 45, 16p.

[3] BENASSI, M.T.; ANTUNES, A.J. A comparison of metaphosphoric and oxalic acids as extractants solutions for the determination of vitamin $\mathrm{C}$ in selected vegetables. Arquivos de Biologia e Tecnologia, v. 31 , n. 4, p. 507-513, 1988.

[4] BRASIL. Ministério da Agricultura. Instrução Normativa $\mathrm{n}^{\circ} 1$, de 7 de Janeiro de 2000. Complementa padrões de identidade e qualidade para suco de laranja. Diário Oficial da União da República Federativa do Brasil, Brasília, 10 de Janeiro de 2000.

[5] BRASIL. Ministério da Agricultura e do Abastecimento. Portaria 544, de 16 de Novembro de 1998. Aprova o Regulamento Técnico para Fixação dos Padrões de Identidade e Qualidade para Preparado Sólido para Refresco. Disponível em:

$<$ htto://oc4j.agricultura.gov.br/agrolegis/do/consultaL ei?op=viewTextual\&codigo $=1150>$ Acesso em: 30 mar. 2004.

[6] CORREA-NETO, R.S.; FARIA. J.A.F. Fatores que influem na qualidade do suco de laranja. Ciênc. Tecnol. Aliment., v. 19, n. 1, p. 153-160, 1999.

[7] DIETARY REFERENCE INTAKES: Applications in Dietary Assessment 2001. National Academy Press <http://books.nap.edu/books/0309071836/html/289 .html> Acesso em: 17 dez. 2002.

[8] DROUZAS, A.E.; TSAMI, E.; SARAVACOS, G.D. 
Microwave/vacuum drying of model fruit gels. Journal of Food Engineering, v. 39, p. 117-122, 1999.

[9] FAO. Citrus commodity notes 2003 - 2004. Commodities and Trade Division, Food and Agriculture Organization of the United Nations, Rome. Disponivel em:

<http://www.fao.org/es/ESC/en/20953/20990/highli ght_28187en.html> Acesso em 13 dez. 2004.

[10] GRAUMLICH, T.R.; MARCY, J.E.; ADAMS, J.P. Aseptically packaged orange juice and concentrate: a review of the influence of processing and packaging conditions on quality. Journal of the Agricultural and Food Chemistry, v. 34, p. 402-405, 1986.

[11] INSTITUTO ADOLFO LUTZ. Normas Analíticas do Instituto Adolfo Lutz - métodos químicos e físicos para análise de alimentos, v. 1, $3^{\text {a }}$ edição, São Paulo, SP, 1985, 181-183p.

[12] JOHNSTON, C.S.; BOWLING, R.D. Stability of ascorbic acid in commercially available oranges juices. Journal of the American Dietetic Association, v. 102, p. 525-529, 2002.

[13] KABASAKALIS, V.; SIOPIDOU, D.; MOSHATOU, E. Ascorbic acid content of commercial fruit juices and its rate loss upon storage. Food Chemistry, v. 70, p. 325$328,2000$.

[14] LAVINAS, F.C.; MARQUES, A.A.; DUTRA, L.L.; VALENTE-MESQUITA, V.L.; LOPES, M.L.M. Variação no teor de ácido ascórbico em sucos de limão industrializados. In: Simpósio Latino Americano de Ciência de Alimentos, 5, 2003, São Paulo. Anais... São Paulo: Unicamp, 2003, cd-rom.

[15] LEE, H.S.; COATES, G.A. Vitamin C in frozen, fresh squeezed, unpasteurized, polyethylene-bottled orange juice: a storage study. Food Chemistry, v. 65, p.165$168,1999$.

[16] LEITÃO, M.F.F. Microbiologia de sucos e produtos ácidos. Boletim do ITAL. Campinas, v. 33, p. 9-42, 1973.

[17] LIMA, V.L.A.G.; MÉLO, E.A.; LIMA, L.S. Avaliação da qualidade de suco de laranja industrializado. Boletim CEPPA, v. 18, n. 1, p. 95-104, 2000.

[18] NOTTER, G.K.; TAYLOR, D.H.; WALKER, L.H. Stabilized lemonade powder. Food Technology, v. 9, n. 10, p. 503-
$505,1955$.

[19] ÖZKAN, M.; AYSEGÜL, K.; CEMEROGLU, B. Effects of hydrogen peroxide on the stability of ascorbic acid during storage in various fruit juices. Food Chemistry, v. 88, p. 591-597, 2004.

[20] POLYDERA, A.C.; STOFOROS, N.G.; TAOUKIS, P.S. Comparative shelf life study and vitamin $\mathrm{C}$ loss kinetics in pasteurized and pressure processed reconstituted orange juice. Journal of Food Engineering, v. 60, p. 21 29, 2003.

[21] SADLER, G.D.; PARISH, M.E.; WICKER, L. Microbial, enzymatic, and chemical changes during storage of fresh and processed orange juice. Journal of Food Science, v. 57, n. 5, p. 1187-1191, 1992.

[22] SHAW, P.E.; MOSHONAS, M.G.. Ascorbic Acid Retention in Orange Juice Stored under Simulated Consumer Home Conditions. Journal of Food Science, v. 56, n. 3, p. 867-868, 1991.

[23] SILVA, P.T.; PEREIRA, C.Q.; ALMEIDA, A.S.; MIGUEL, M.A.L.; LOPES, M.L.M.; VALENTE-MESQUITA, V.L. Efeito da temperatura e do tempo de estocagem sobre o teor de ácido ascórbico e a estabilidade microbiológica de suco de laranja 'Pêra'. In: Simpósio Latino Americano de Ciência de Alimentos, 5, 2003, São Paulo. Anais... São Paulo: Unicamp, 2003, cd-rom.

[24] TETRA PACK. Empreendedor: inovação, gestão e valor aos negócios. Tetra Pack lança campanha para incentivar consumo de suco pronto e água de coco. Disponivel em:

<http:/ / www.empreendedor.com.br/ler.php?cod=703>. Acesso em: 07 jan. 2005

[25] VALENTE-MESQUiTA, V.L.; LOPES, M.L.M.; SABINO, G.S.; SILVA, P.T.; ALVES, B.C. Teor de vitamina C em suco de cultivares de laranja (Citrus sinensis) e em diferentes sucos industrializados. Nutrição Brasil, v. 1, n. 1 , p. 34-39, 2002 .

\section{6 - AGRADECIMENTOS}

Os autores agradecem à Fundação Carlos Chagas Filho de Amparo à Pesquisa do Estado do Rio de Janeiro (FAPERJ) e à Fundação Universitária José Bonifácio (FUJB) pelo apoio financeiro. 